\title{
Erection Simulation of Steel Connected Precast Concrete Components for Logistics Buildings
}

\author{
Seunghyun Son', Jeeyoung Lim¹, Kim Do Yeong1, Yang-Ki Oh², Sunkuk Kim¹ \\ ${ }^{1}$ Department of Architectural Engineering, Kyung Hee University \\ 1732 Deogyeong-daero, Giheung-gu, Yongin-si, Gyeonggi-do, Republic of Korea \\ seunghyun@khu.ac.kr; jyounglim@khu.ac.kr; dream1968@khu.ac.kr; kimskuk@khu.ac.kr \\ ${ }^{2}$ Department of Architecture, Mokpo National University \\ 61 dorim-ri, 1666 Yeongsan-ro, Cheonggye-myeon, Muan-gun, jeonnam, South Korea \\ oh@mokpo.ac.kr
}

\begin{abstract}
As Internet commerce explosively increases, the construction of large logistics buildings worldwide is exploding. Most of these buildings have the characteristics of long span and heavy loaded and use precast concrete components, a pin joint structure, for rapid construction. However, due to the construction safety and structural stability, the pin joint structure has many limitations in the erection of the PC (precast concrete) member, which increases the time and cost. The structural frame connected with steel joints between precast concrete components, called SMART frame, which solve these constraints and risks, have been developed. The objective of this study is to simulate the erection of steel connected precast concrete components for long span and heavy loaded logistics buildings. For this study, the authors select a case site erected by existing PC components, and then compare the results with the SMART frame erection simulations.
\end{abstract}

Keywords: Erection Simulation, Precast Concrete, Steel Joint, Logistics Building, Composite PC.

\section{Introduction}

As Internet commerce has explosively increased, more large logistics buildings are built worldwide. They are mostly characterized by long span and heavy load, and precast concrete (PC) components are applied for rapid construction. It is to simply install the components, and columns and beams are connected with pins (pin-joint structure). Therefore, its lateral load must be supported with a large shear wall or RC structure core [1].

However, it leads to a tremendous amount of construction cost, making it difficult for the contractor to afford the cost. Accordingly, it results in construction delay as it accounts for the critical process of erection [2]. SMART frame developed to solve these problems is a composite precast concrete structure system that adopts the advantages of steel frame and reinforced concrete [3].

Several studies have already proven that SMART frame is structurally stable, constructible and economically feasible, and it is far superior to existing steel frame systems when it comes to shortened construction period [4]. In particular, the biggest merit of SMART frame is that it ensures structural stability as soon as it is erected because of the moment joint [5]. For reference, SMART is the acronym of Scientific, Measurable, Attainable, Reliable, and Timely.

It is expected that there will be a significant improvement in time compared to the existing PC structures when SMART frame with the above advantages is applied to long-span and heavy-loaded buildings like large logistics centres. For its verification, a case site built with the existing PC structure is selected and compared with the erection simulation of SMART frame.

Thus, the purpose of this study is to conduct an 'Erection Simulation of Steel Connected Precast Concrete Components for Long Span and Heavy Loaded Logistics Buildings'. To do so, the study complies with the following procedure.

First, the developed SMART frame is theoretically reviewed. Based on the reviews, the characteristics of this construction method are identified.

Second, the characteristics of SMART frame are compared with those of the existing PC structure for analyses. Then, its pros and cons upon construction of long span, heavy-loaded logistics buildings are drawn. 
Third, a case site applied with pin-joint is chosen and an erection simulation of SMART frame is performed.

Lastly, the simulation result is compared in the aspect of construction time (period), and effective ways of applying SMART frame are discussed.

\section{Preliminary Study}

\subsection{SMART Frame}

SMART Frame is a Rahmen steel structure system composed of composite PC columns and beams [6]. As illustrated in Figure 1 on SMART frame, the steel frame components are inserted in both ends of beams and column-beam joint parts. It has a similar function as steel connections when precast concrete columns are connected to beams. In other words, SMART frame ensures structural stability upon its erection owing to the moment joint.
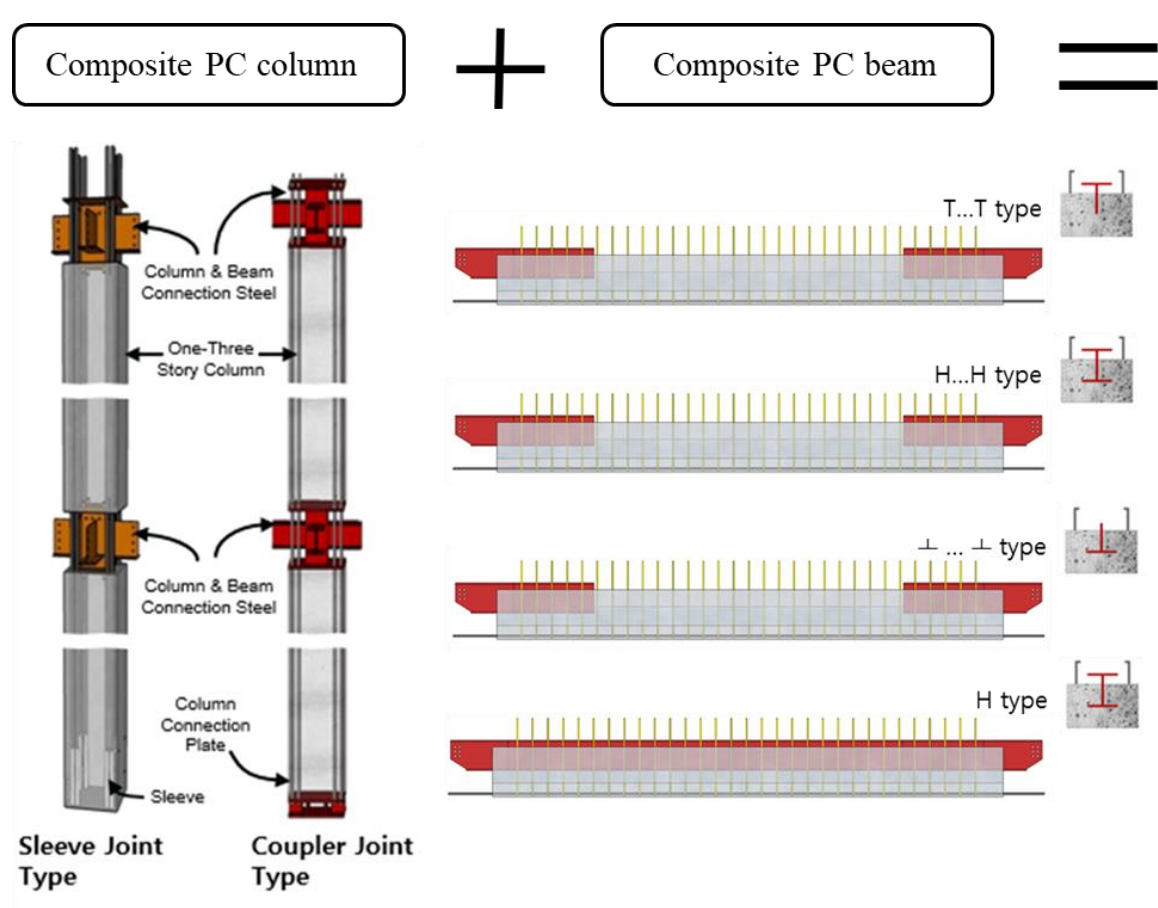

Sleeve
Type Type

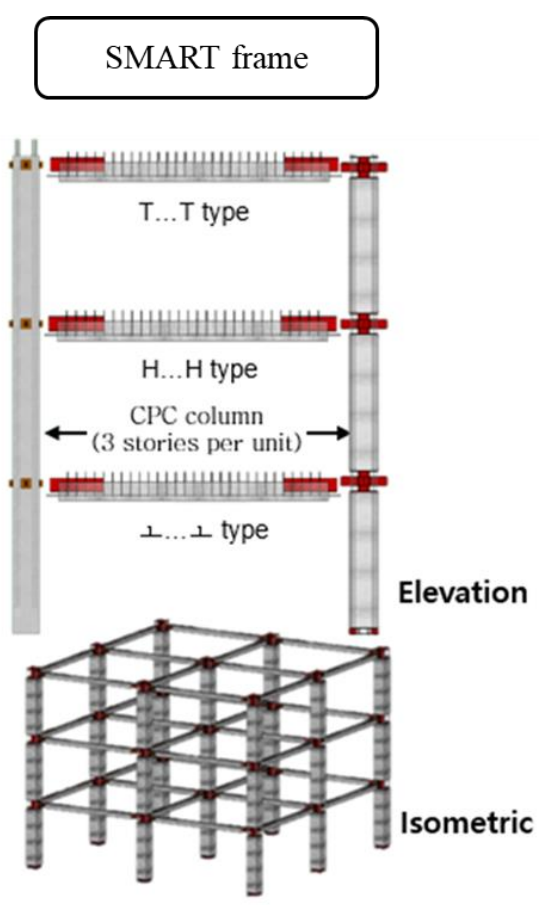

Fig. 1: SMART Frame Composition [6].

Therefore, SMART frame not only secures structural stability, but also allows the precast concrete structure to be constructed with the same speed and method applied to the steel frame structure. These advantages lead to shortened construction time and reduced cost. [7].

\subsection{Pros and Cons of SMART Frame}

The characteristics of SMART frame studied in the previous section are compared with those of PC structure when applied to long-span, heavy-loaded buildings. Then, its advantages are verified. The comparison results are as shown in Table 1. 
Table 1: PC Structure vs. SMART Frame.

\begin{tabular}{|c|c|c|}
\hline Classification & PC structure & SMART frame \\
\hline Main components & Standard PC(RC) & Composite PC(SRC) \\
\hline Joint structure & Pin-joint & Moment-joint \\
\hline Erection method & Floor-by-floor method & $\begin{array}{c}\text { Floor-by-floor, Section and frame lift-up method } \\
\text { (same as the steel frame erection) }\end{array}$ \\
\hline $\begin{array}{c}\text { Equipment operation } \\
\text { plan }\end{array}$ & $\begin{array}{c}\text { Limited equipment operation owing to the } \\
\text { application of floor-by-floor method }\end{array}$ & $\begin{array}{c}\text { Various equipment operations plans owing to the } \\
\text { application of section method }\end{array}$ \\
\hline Core role & Shear wall supporting the lateral load & Simple vertical passage \\
\hline Slab system & $\begin{array}{c}\text { Essential to use expensive PC slabs } \\
\text { (Double-T, RPS and etc.) }\end{array}$ & $\begin{array}{c}\text { Deck plate system with good constructability is } \\
\text { applicable (Deep Deck and etc.) }\end{array}$ \\
\hline Critical system & Mainly RC core & Assembly of PC components \\
\hline Lateral resistance system & $\begin{array}{c}\text { Separate shear walls (wet construction), core } \\
\text { walls (wet construction), brace and more } \\
\text { need to be installed }\end{array}$ & No installation necessary \\
\hline Construction safety & Lateral reinforcement needed & Lateral reinforcement not needed \\
\hline
\end{tabular}

According to Table 1, SMART frame has the following advantages when compared with the PC structure.

Firstly, SMART frame ensures structural stability immediately after it is assembled owing to its moment joint. Accordingly, no additional lateral resistance system is needed and it shortens the time required for construction [8].

Secondly, unlike the existing PC structure, various erection methods, including floor-by-floor, section-by-section and frame lift-up methods can be applied. It allows a wide range of equipment operation plans, and the SMART frame construction method incredibly reduces the time required for construction, when compared with that of the existing PC method [9].

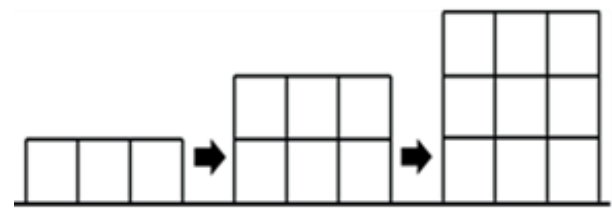

(a)

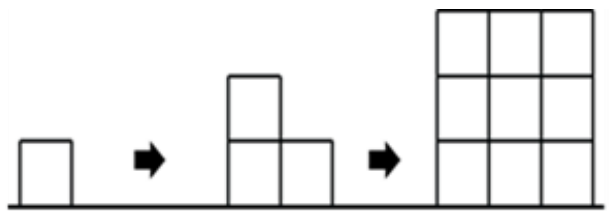

(b) Cascade Building

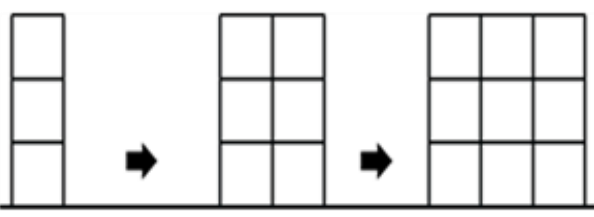

(c) Section by Section

Fig. 2: Erection of PC Structure.

For reference, there are mainly 3 methods for erecting PC structures as shown in Figure 2 - Floor by Floor, Cascade Building and Section by Section.

As illustrated in Figure 2(a), the floor-by-floor method is to erect components of the next floor after every floor is completed, which is one of the general construction methods. The cascade building method is to pile up PC components that are similar to stairs as shown in Figure 2(b) [10]. Both methods shown in Figure 2(a) and (b) are applicable to the general pin-joint PC structure.

The section by section method illustrated in Figure 2(c) is to erect all components of the corresponding span at once. This is extremely dangerous when applied to the general pin-joint PC structure. As the components are erected for one span, its construction is very unstable.

However, since structural stability is realized as soon as SMART frame is erected, the section by section method is applicable as well [11]. When SMART frame with this exceptional advantage is applied to long-span, heavy-loaded building such as large logistics buildings, a considerable improvement in construction time is anticipated.

For the study, a case site of the existing PC structure is chosen and its result is compared with the simulation result of SMART frame erection. 


\section{Case Study}

A case site of the study is a large logistics center of PC structure built in the general industrial district located in Pungsae, Cheonan. A bird's eye view of the building and its site conditions are as shown in Figure 3, and the details are described in Table 2.

There was a trench that was about $5 \mathrm{~m}$ deep in the northwest direction, so a mobile crane could not enter this area. It could not enter from the northeast direction because a building was nearby as well. Thus, a mobile crane used for erection of PC components had to enter from the southeast or southwest direction.

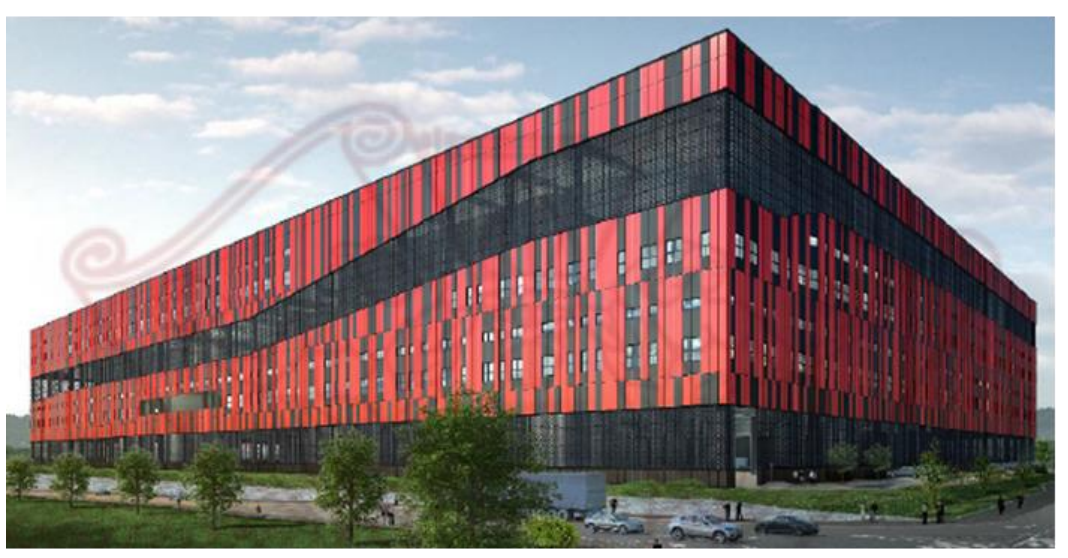

(a) Bird's eye view of the case site

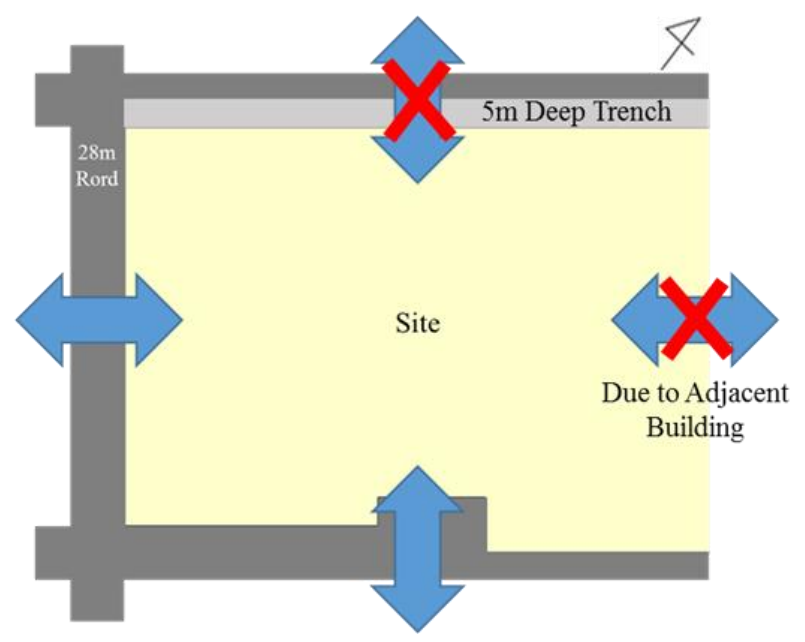

(b) Site condition

Fig. 3: Bird's Eye View of the Case Site and its Site Conditions.

Table 2: Details of the Case Site.

\begin{tabular}{|c|c|}
\hline Item & Description \\
\hline Site location & Cheonan-si, Chungcheongnam-do \\
\hline Lot area & $53,055.60 \mathrm{~m} 2$ \\
\hline Total floor area & $167,612.82 \mathrm{~m} 2$ \\
\hline Building area & $42,406.07 \mathrm{~m} 2$ \\
\hline Floor area ratio & $235.87 \%$ \\
\hline Building coverage & $79.93 \%$ \\
\hline Building size & Four stories above ground \\
\hline Structure & $\begin{array}{c}\text { PC structure; reinforced concrete structure, steel frame structure, steel } \\
\text { framed reinforced concrete structure }\end{array}$ \\
\hline Use & Storage facility \\
\hline
\end{tabular}

As described above, there were two original erection plans established in consideration of the site condition which are illustrated in Figure 4 (a) and (b). In case of ALT-1 shown in Figure 4 (a), when a section excluding the crane passage is completed, the components of the crane passage are erected to complete the steel frame work.

However, it was expected to be dangerous in the pin-joint PC structure because a crane would move toward the inner side and there was a limitation to the crane boom length and interference when erecting PC components.

Thus, the central passage was deleted and the site was divided into three new zones as shown in Figure 4 (b) of ALT2. Unlike the first plan, AlT-2 had an independent passage for 3 cranes, so the cranes would move around without trouble.

ALT-2 was chosen to erect PC components for the case site. Figure 6 shows the erection process that was actually adopted for the case site using a 3D modeling tool. 


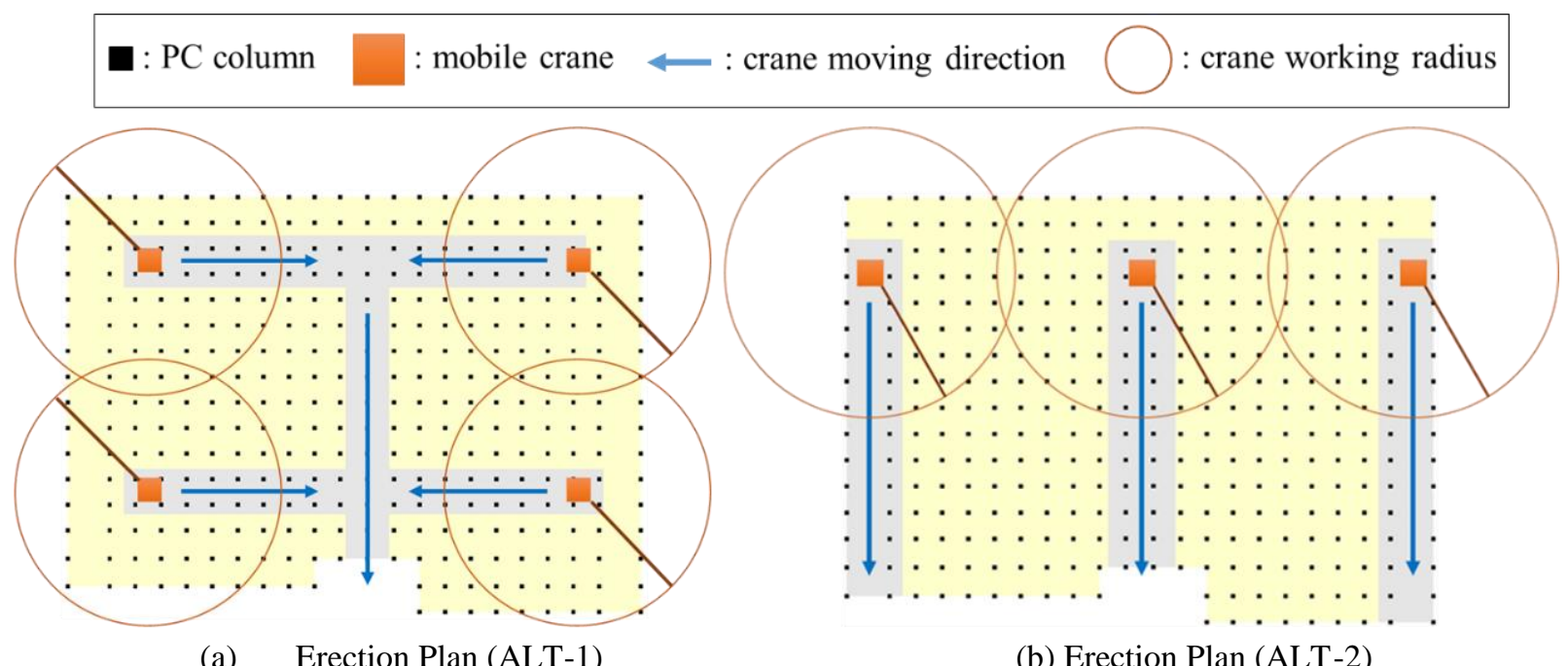

(a) Erection Plan (ALT-1)

(b) Erection Plan (ALT-2)

Fig. 4: Erection Plans for the Case Site.

\section{Erection Simulation of SMART frame}

The greatest advantage of SMART frame is that its structural stability is ensured upon erection owing to the moment joint. The SMART frame erection plan for the study is as shown in Figure 6, and it is set taking into account of the site conditions shown in Figure 3. Various erection plans may be established considering the site conditions because SMART frame can adopt the section by section method.

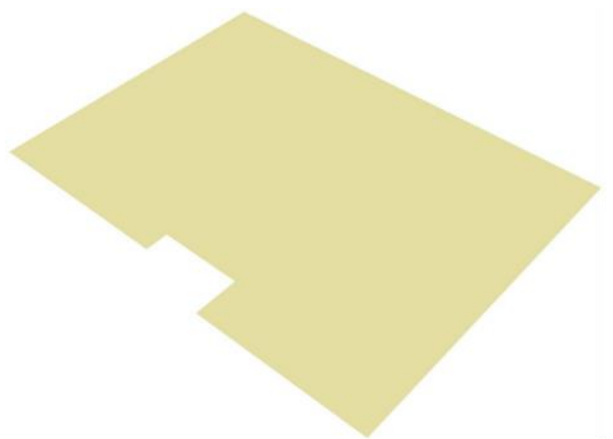

(a) $\mathrm{M}+0$

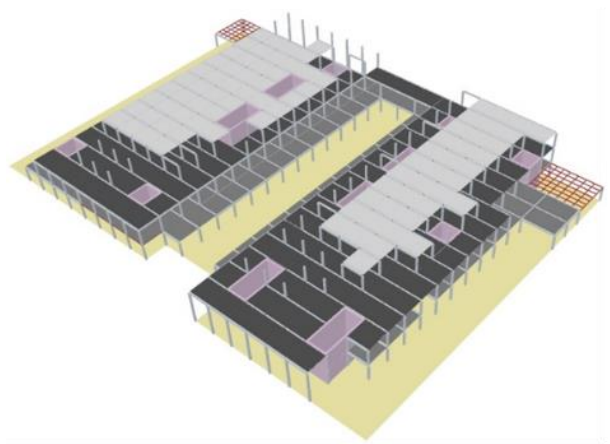

(d) $\mathrm{M}+5$

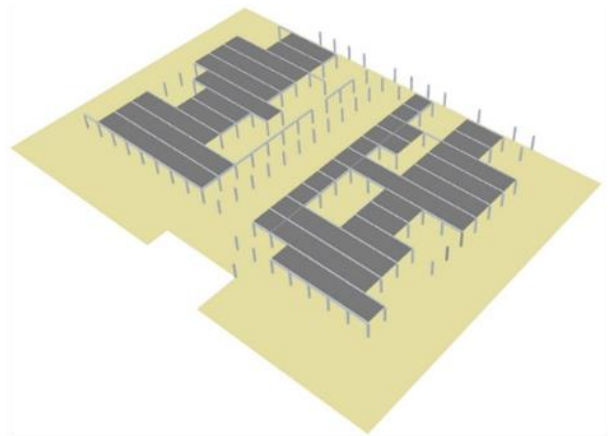

(b) $\mathrm{M}+1$

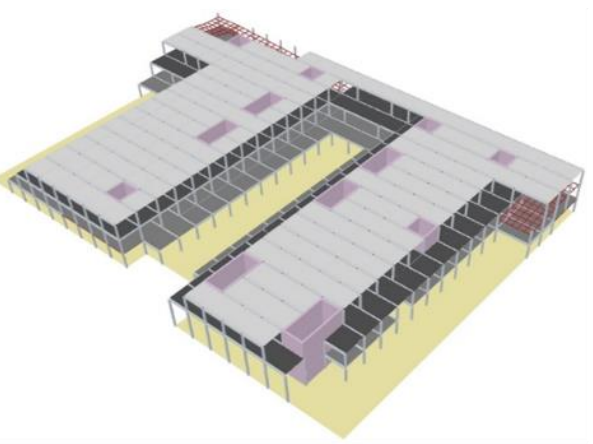

(e) $\mathrm{M}+7$

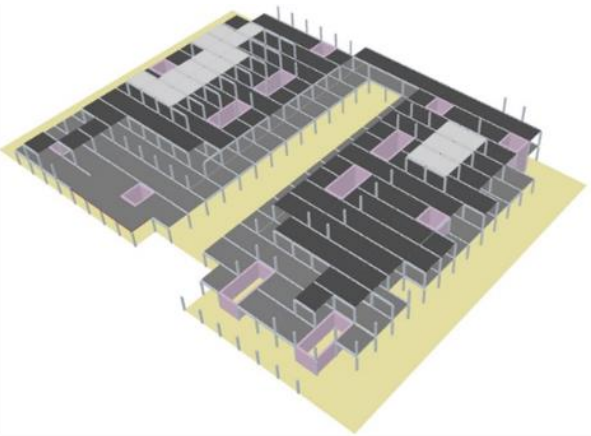

(c) $\mathrm{M}+3$

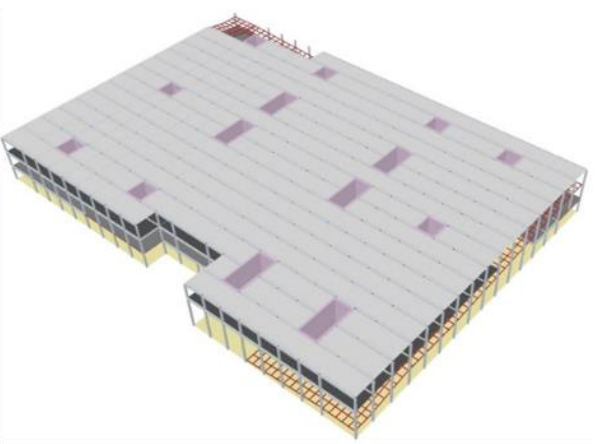

(f) $\mathrm{M}+9$

Fig. 5: Erection Simulation of Pin-Joint Frame. 


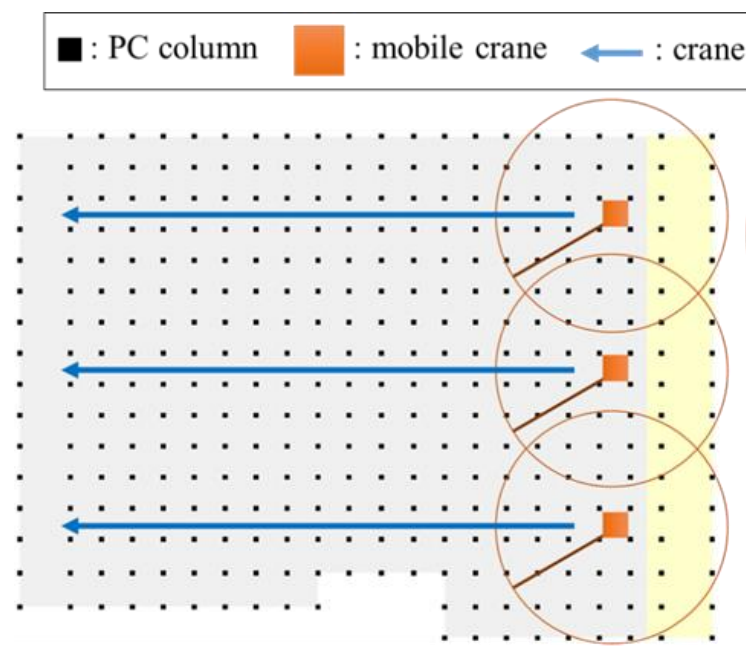

(a) Erection Plan (ALT-1)

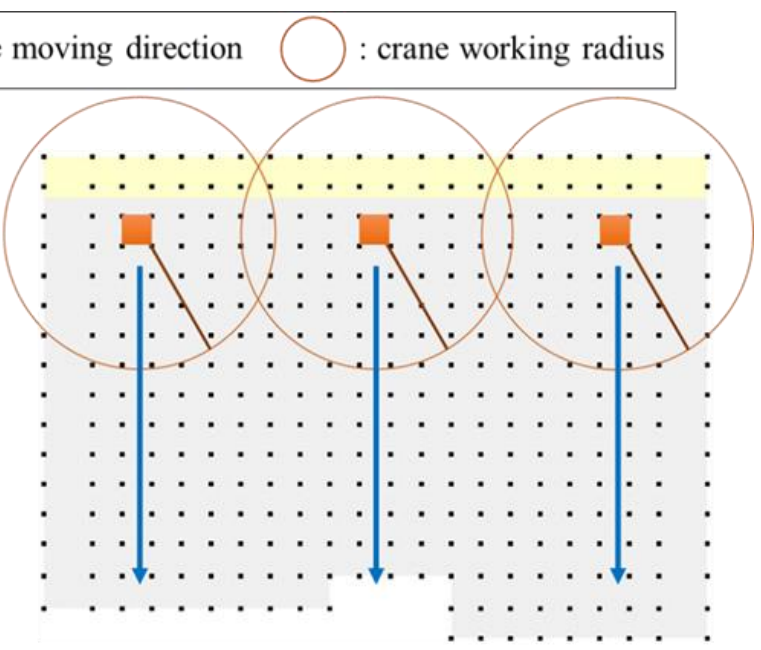

(b) Erection Plan (ALT-2)

Fig. 6: SMART Frame Erection Plan.

Based on ALT-2 shown in Figure 6 (b), an erection simulation was conducted with the section by section method for the study. The 3D modeling tool was used to realize the images shown in Figure 7, and the time required for SMART frame erection was estimated based on the actual hours of PC component erection measured at the case site.
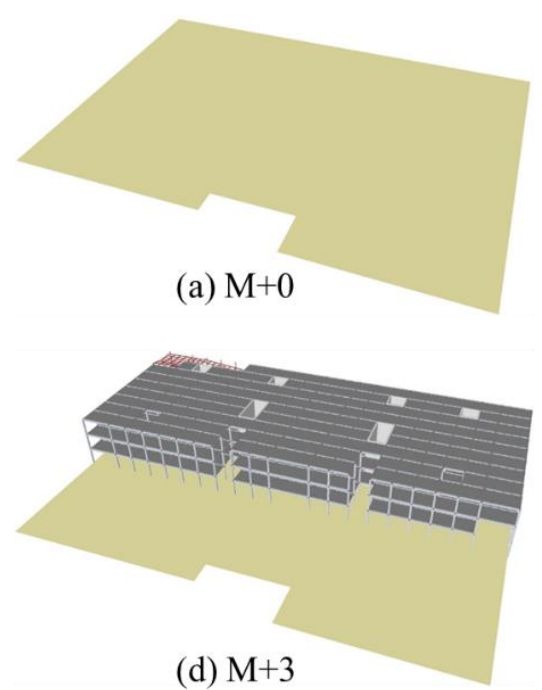

(d) $\mathrm{M}+3$
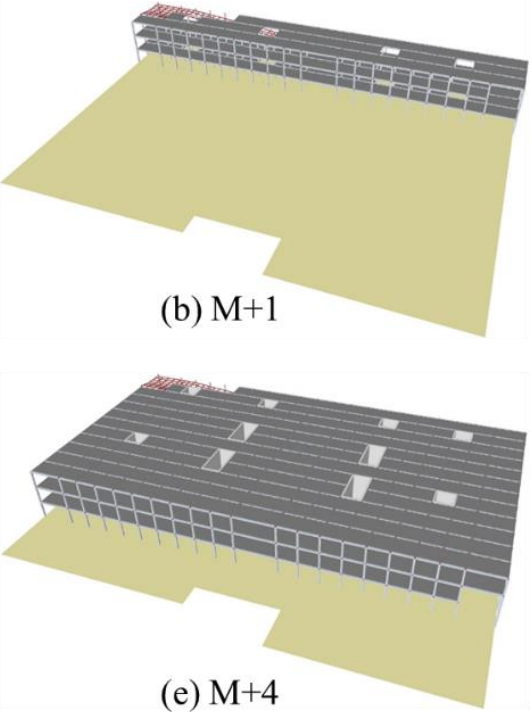

(e) $\mathrm{M}+4$
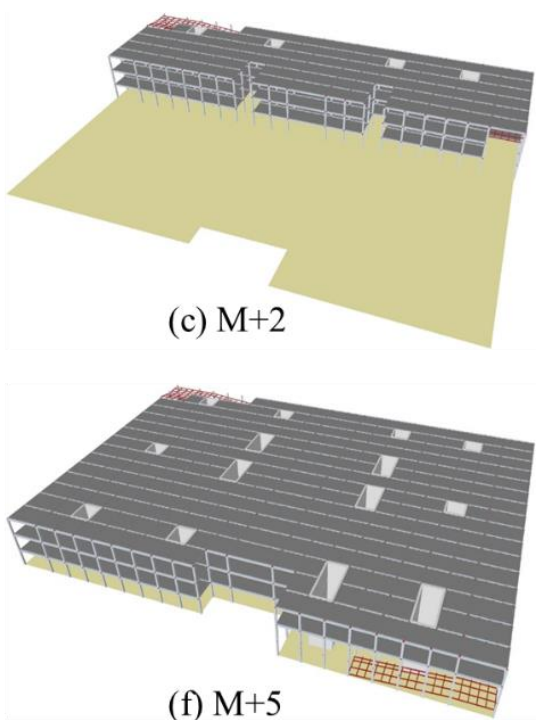

Fig. 7: Erection simulation of SMART frame.

It was based on the assumption that the time required for SMART frame erection is calculated based on the actual values measured at the large PC-structure logistics center. The assumptions are as described in Table 3.

Table 3: Assumptions.

\begin{tabular}{|c|c|c|}
\hline Type & Unit & Description \\
\hline Daily working hours & hours & 8 hours \\
\hline PC column erection time & minutes & $18 \mathrm{~min} /$ column \\
\hline PC beam erection time & minutes & $12 \mathrm{~min} / \mathrm{beam}$ \\
\hline PC slab erection time & minutes & $12 \mathrm{~min} / \mathrm{slab}$ \\
\hline
\end{tabular}


As described in Table 3, it takes 8 hours a day for PC erection, and any delay in construction caused by delayed transport of PC components and so forth was not taken into consideration. The PC erection time was calculated by rounding off the nearest whole number by day. Any crane movement between sections and other necessary works, excluding PC erection were considered, and 0.5 day per section was applied. In addition, the time required for construction of the steel frame section based on the area was roughly estimated for application. Figure 8 shows the result of estimation based on the assumptions, and the time required for each zone was calculated as follows.

- A Zone: 75days (3.8 months); B Zone: 96 days (4.8 months); C Zone: 80 days (4 months).

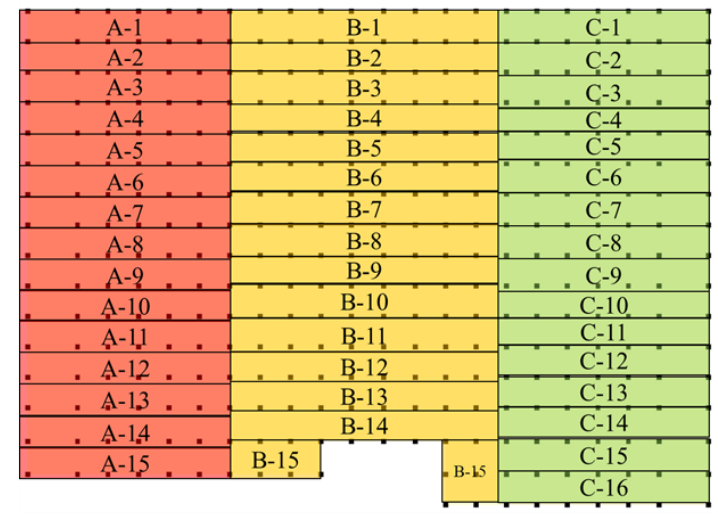

(a) Erection Zone

\begin{tabular}{|c|c|c|c|c|c|c|c|c|c|c|c|c|c|c|c|c|c|c|c|c|c|}
\hline \multirow{2}{*}{ Type } & \multirow{2}{*}{$\begin{array}{c}\text { Month } \\
\text { Week } \\
\end{array}$} & \multicolumn{4}{|c|}{$\mathrm{M}+1$} & \multicolumn{4}{|c|}{$M+2$} & \multicolumn{4}{|c|}{$\mathbf{M}+3$} & \multicolumn{4}{|c|}{$\mathrm{M}+4$} & \multicolumn{4}{|c|}{$\mathrm{M}+5$} \\
\hline & & 1 & 2 & 3 & 4 & 5 & 6 & 7 & 8 & 9 & 10 & 11 & 12 & 13 & 14 & 15 & 16 & 17 & 18 & 19 & 20 \\
\hline \multirow{2}{*}{\multicolumn{2}{|c|}{ A Zone }} & A-1 & A-2 & A-3 & A-4 & A-5 & A-6. & A-7 & A-8 & A-9 & A-10 & A-11 & 1 A-12 & A-13 & A-14 & A-15 & & & & & \\
\hline & & & & & & & & & & & & & & & & & & & & & \\
\hline \multirow{2}{*}{\multicolumn{2}{|c|}{ B Zone }} & B-1 & B-2 & B. & $3 \quad B$ & 4 & B-5 & B-6 & B-7 & $7 \mathrm{~B}$ & $8 \quad B$ & $-9 \quad 1$ & B-10 & B-11 & B-1 & $2 \mathrm{~B}-$ & $13 \mathrm{~B}-1$ & $4 \quad 1$ & B-15 & & \\
\hline & & & & & & & & & & & & & & & & & & & & & \\
\hline \multirow{2}{*}{\multicolumn{2}{|c|}{ C Zone }} & $\mathrm{C}-1$ & $\mathrm{C}-2$ & $\mathrm{C}-3$ & $\mathrm{C}-4$ & $\mathrm{C}-5$ & $\mathrm{C}-6$ & $\mathrm{C}-7$ & $\mathrm{C}-8$ & $\mathrm{C}-9$ & C-10 & $\mathrm{C}-11$ & $1 \mathrm{C}-12$ & $\mathrm{C}-13$ & $\mathrm{C}-14$ & C-15 & $\mathrm{C}-16$ & & & & \\
\hline & & & & & & & & & & & & & & & & & & & & & \\
\hline
\end{tabular}

(b) Erection Schedule

Fig. 8: Erection Zone and Erection Schedule.

As a result, it took about 40 50\% of the time required for erection when SMART frame was applied to the case site. This is far more outstanding than the pin-joint structure. This may be because of structural stability that is realized immediately upon erection. Additionally, the section by section method can be applied instead of the floor by floor method which is one of the existing erection methods for pin-joint structures, and it may reduce the time required for construction.

\section{Conclusion}

Most of large logistics buildings are characterized by their long span and heavy load, and the PC component, pin-joint structure is applied for rapid construction. Since the PC components of the upper floor cannot be erected until concrete is poured into the joint, there are limitations for PC erection and it increases the construction cost and time.

Thus, the study applies a composite PC structure, SMART frame that has improved the characteristics of pin-joint structures to the actual case for erection simulation. Its effect of reducing the construction time was verified through the simulation.

The study results are as described below.

Firstly, the structural characteristics and differences of the pin-joint PC structure and SMART frame were analyzed to draw each structural system's pros and cons.

Secondly, an erection plan using SMART frame was established for the pin-joint PC structure case, and an erection simulation was conducted. As a result of the simulation, it took 75 days (3.8 months) for A Zone, 96 days (4.8 months) for $\mathrm{B}$ Zone and 80 days (4 months) for $\mathrm{C}$ Zone. The total time required for erection was 4.8 months. This is only 40 50\% of the time required for erection of the existing PC structure. 
Therefore, the study verified the advantage of SMART frame, a composite PC structure, in reducing the construction time compared to the pin-joint structure when applied to long-span, heavy-loaded buildings like large logistics buildings. It is expected that SMART frame may significantly reduce the construction time when applied to large logistics centres. Additionally, it is believed that SMART frame is useful in deciding the construction methods and making necessary decisions for building projects because various erection methods, including the floor by floor, section by section and frame lift-up methods can be applied.

\section{Acknowledgements}

This work was supported by the National Research Foundation of Korea (NRF) grant funded by the Korea government (MOE) (No. 2017R1D1A1B04033761).

\section{References}

[1] S. H. Lee, W. K. Hong, C. Y. Lim, S. K. Kim, "A Dynamic Erection Simulation Model of Column-Beam Structures Using Composite Precast Concrete Components," Journal of Intelligent \& Robotic Systems, vol. 79, no. 3-4, pp. 537-547, 2015.

[2] J. Y. Hu, "Development of Moment Connection of Precast Concrete Columns Using Steel Plates and Nonlinear Inelastic Finite Element Analysis," M. A Thesis, Dept. Architectural Engineering, Kyung Hee University, 2016.

[3] S. H. Lee, S. E. Kim, G. H. Kim, J. K. Joo, S. K. Kim, "Analysis of structural work scheduling of green frame (focusing on apartment buildings)," Journal of the Korea Institute of Building Construction, vol. 11, no. 3, pp. 301309, 2011.

[4] W. K. Hong, J. M. Kim, S. C. Park, S. I. Kim, S. G. Lee, H. C. Lee, K. J. Yoon, "Composite beam composed of steel and pre-cast concrete (modularized hybrid system) Part II: analytical investigation," The Structural Design of Tall and Special Buildings, vol. 18, no. 8, pp. 891-905, 2009.

[5] W. K. Hong, S. C. Park, H. C. Lee, J. M. Kim, S. I. Kim, S. G. Lee, K. J. Yoon, “Composite beam composed of steel and precast concrete (modularized hybrid system). Part III: application for a 19-storey building," The Structural Design of Tall and Special Buildings, vol. 19, no. 6, pp. 679-706, 2010.

[6] W. K. Hong, S. I. Kim, S. C. Park, J. M. Kim, S. G. Lee, K. J. Yoon, S. K. Kim, "Composite beam composed of steel and precast concrete (modularized hybrid system). Part IV: application for multi-residential housing," The Structural Design of Tall and Special Buildings, vol. 19, no. 7, pp. 707-727, 2010.

[7] C. Y. Lim, S. H. Lee, S. K. Kim, "Embodied energy and $\mathrm{CO}_{2}$ emission reduction of a column-beam structure with enhanced composite precast concrete members," Journal of Asian Architecture and Building Engineering, vol. 14, no. 3, pp. 593-600, 2015.

[8] S. K. Kim, W. K. Hong, J. H. Kim, J. T. Kim, "The development of modularized construction of enhanced precast composite structural systems (Smart Green frame) and its embedded energy efficiency," Energy and Buildings, vol. 66, pp. 16-21, 2013.

[9] W. H. Cho, "Construction planning and effectiveness of logistics facilities using composite precast component," M. A. Thesis, Dept. Architectural Engineering, Kyung Hee University, 2017.

[10] W. K. Hong, G. J. Lee, S. H. Lee, S. K. Kim, "Algorithms for in-situ production layout of composite precast concrete members," Automation in Construction, vol. 41, pp. 50-59, 2014.

[11] S. H. Lee, J. T. Kim, S. K. Kim, "An analysis of $\mathrm{CO}^{2}$ reduction effect of the composite precast concrete structure," Indoor and Built Environment, 2011. 